\title{
Operando SXRD of E-ALD deposited sulphides ultra-thin films: Crystallite strain and size
}

\author{
Andrea Giaccherini ${ }^{a, *}$, Francesca Russo ${ }^{a}$, Francesco Carlà ${ }^{\mathrm{b}}$, Annalisa Guerri ${ }^{\mathrm{a}}$, \\ Rosaria Anna Picca ${ }^{c}$, Nicola Cioffic ${ }^{c}$, Serena Cinotti ${ }^{a}$, Giordano Montegrossi ${ }^{\mathrm{d}}$, \\ Maurizio Passaponti ${ }^{\mathrm{a}}$, Francesco Di Benedetto ${ }^{\mathrm{d}, \mathrm{e}}$, Roberto Felici ${ }^{\mathrm{f}}$, Massimo Innocenti $^{\mathrm{a}}$ \\ a Department of Chemistry, Università Degli Studi di Firenze, Via della Lastruccia 3-13, 50019, Sesto Fiorentino (FI), Italy \\ ${ }^{\mathrm{b}}$ ESRF, 6, Rue Horowitz, F-BP 220, 38043, Grenoble, Cedex, France \\ ${ }^{\mathrm{c}}$ Department of Chemistry, Università degli Studi di Bari, Via E. Orabona, 4-70125 Bari, Italy \\ d IGG-CNR, via G. La Pira 4, 50121, Italy \\ e Department of Earth Sciences, Università Degli Studi di Firenze, Via La Pira 4, 50121 Firenze, Italy \\ f SPINCNR, Area della Ricerca di Roma 2 - Tor Vergata, Via del Fosso del Cavaliere 100, 00133 Roma, Italy
}

\section{A R T I C L E I N F O}

\section{Article history:}

Received 8 March 2017

Received in revised form 21 July 2017

Accepted 31 July 2017

Available online 5 August 2017

\section{Keywords:}

SXRD

ECALE

E-ALD

Photovoltaics

Water-splitting

Ultra-thin films

\begin{abstract}
A B S T R A C T
Electrochemical Atomic Layer Deposition (E-ALD), exploiting surface limited electrodeposition of atomic layers, can easily grow highly ordered ultra-thin films and 2D structures. Among other compounds $\mathrm{Cu}_{\mathrm{x}} \mathrm{Zn}_{\mathrm{y}} \mathrm{S}$ grown by means of E-ALD on $\mathrm{Ag}(111)$ has been found particularly suitable for the solar energy conversion due to its band gap $(1.61 \mathrm{eV})$. However its growth seems to be characterized by a micrometric thread-like structure, probably overgrowing a smooth ultra-thin films. On this ground, a SXRD investigation has been performed, to address the open questions about the structure and the growth of $\mathrm{Cu}_{\mathrm{x}} \mathrm{Zn}_{\mathrm{y}} \mathrm{S}$ by means of E-ALD. The experiment shows a pseudo single crystal pattern as well as a powder pattern, confirming that part of the sample grows epitaxially on the $\mathrm{Ag}(111)$ substrate. The growth of the film was monitored by following the evolution of the Bragg peaks and Debye rings during the E-ALD steps. Breadth and profile analysis of the Bragg peaks lead to a qualitative interpretation of the growth mechanism. This study confirms that $\mathrm{Zn}$ lead to the growth of a strained $\mathrm{Cu}_{2} \mathrm{~S}$-like structure, while the growth of the thread-like structure is probably driven by the release of the stress from the epitaxial phase.
\end{abstract}

(c) 2017 Elsevier B.V. All rights reserved.

\section{Introduction}

The energy issue of modern society is linked to the limited availability of non-renewable fuels coupled to the increasing levels of global pollution, approaching an environmental overshoot. This implies the need for a rapid development in materials and techniques for renewable energy applications. An increase in efficiency and sustainability of the solar cells necessarily requires the use of materials consisting of elements whose availability will support the diffusion of the photovoltaic technology at a global level over the actual extent represented by the silicon-based solar cells. At the same time, the use of such materials should ensure a lower environmental impact, in a Full Life Cycle Assessment (FLCA), and the device production must be done through less energy-intensive methods, thus increasing the Energy Return Over Energy Investment (EROEI). For these reasons, the scientific community is focusing its attention

\footnotetext{
* Corresponding author.

E-mail address: andrea.giaccherini@unifi.it (A. Giaccherini).
}

on new compounds based on economic and low-environmental impact elements such as $\mathrm{Cu}, \mathrm{Sn}, \mathrm{Fe}$ and $\mathrm{Zn}$. A possibility to obtain high quality thin film semiconductors relies on exploiting electrochemical deposition. This technique is a very attractive method to produce compound semiconductors with different stoichiometry and high crystallinity because of its easiness of implementation, its relatively low cost, its capability of growing the selected materials onto substrates of any shape and dimensions.

Chalcogenide nanomaterials are interesting candidates for photovoltaic applications due to the reasons well-explained by Innocenti et al. [1]. Chalcogenides can be grown by means of Electrochemical Atomic Layer Epitaxy (ECALE) [2]. This technique consists in the electrodeposition of alternating metallic and nonmetallic monolayers in a cycle which can be repeated several times and which exploits reactions limited by the surface (SLR - Surface Limited Reactions), including UnderPotential Depositions (UPD). This method is also referred as E-ALD (Electrochemical Atomic Layer Deposition), when the deposit cannot be considered strictly epitaxial [3]. 
Semiconducting material based on elements such as $\mathrm{Cu}, \mathrm{Sn}, \mathrm{Fe}$ and $\mathrm{Zn}$, are considered the most promising candidates to overtake the current generation of light absorbing materials for thin-film solar cells [4]. These materials are expected to have a very favorable FLCA due to their natural abundance and very low toxicity. Moreover, the E-ALD of metal sulphides from aqueous solution represents a very efficient alternative to high-temperature and high-pressure methods.

Previous studies were successful in the E-ALD growth of thin films with binary and ternary composition, such as $\mathrm{Cu}-\mathrm{S}, \mathrm{Cu}-\mathrm{Zn}-$ $\mathrm{S}$ and $\mathrm{Cu}-\mathrm{Sn}-\mathrm{S}$, and demonstrated the possibility of growing these materials with high crystallinity, exerting a close control of stoichiometry, morphology and semiconducting properties [5-7].

Mixed $\mathrm{Cu}-\mathrm{Zn}$ sulphides are particularly interesting from a fundamental standpoint, since the two cations are supposed to have scarce structural and valence affinity when in sulfide systems. In nature, $\mathrm{Cu}$ sulfide minerals and $\mathrm{Zn}$ sulfide minerals are commonly associated in most ores; still they have poor or absent solubility. The redox properties of $\mathrm{Cu}$ in sulphides (i.e. the instability of its divalent state in such environment) seems to play a critical role in limiting the stability of $\mathrm{Cu}-\mathrm{Zn}-\mathrm{S}$ structures in thermodynamically equilibrated phases. This critical point can be overcome under out-of-equilibrium conditions of synthesis. As well as we know, few studies report the attempt of synthesizing $\mathrm{CuZnS}_{2},(\mathrm{Cu}, \mathrm{Zn}) \mathrm{S}$ or $\mathrm{Cu}_{2} \mathrm{Zn}_{2} \mathrm{~S}_{3}$ [7-12]. Uhuegbu et al. synthesized $\mathrm{Cu}-\mathrm{Zn}-\mathrm{S}$ compounds through a one-pot synthesis with metal chlorides and thiourea in solution, assisted by opportune complexing agents [7]. Conversely, Aduloju et al. doped $\mathrm{ZnS}$ from a contact solution of $\mathrm{Cu}^{2+}$, the resulting products being homogenized by a mild temperature treatment $\left(300^{\circ} \mathrm{C}\right)$ Kitagawa et al. claimed to have successfully deposited thin films of $\mathrm{Cu}_{2} \mathrm{Zn}_{2} \mathrm{~S}_{3}$ by spray pyrolysis [10]. Bagdare et al. claimed to have obtained a nanocrystalline thin films of $\mathrm{Cu}_{\mathrm{x}} \mathrm{Zn}_{1-\mathrm{x}} \mathrm{S}$ by means of chemical bath deposition [11]. Moreover, Adelifard et al. obtained claimed to have obtained a biphasic CuS-ZnS thin film by means of spray pyrolysis [12]. Unfortunately, these studies did not provide decisive evidences of the attainment of a monophasic compound, or, at least, of a partial solid solution between $\mathrm{Cu}$ - and Zn-sulfide phases. In this context, E-ALD was considered a good candidate to overcome the thermodynamics constraints in the $\mathrm{Cu}-$ $\mathrm{Zn}$ sulphides to obtain a metastable phase. Our group attempted to grow $\mathrm{Cu}_{\mathrm{x}} \mathrm{Zn}_{\mathrm{y}} \mathrm{S}$ by means of E-ALD on $\mathrm{Ag}(111)$. However, the electrochemical characterization of the deposited film highlighted a $\mathrm{Zn}$-deficiency $[6,13]$. It is worth to notice that a similar result was pointed out with reference to $\mathrm{Cd}_{\mathrm{x}} \mathrm{Zn}_{1-\mathrm{x}} \mathrm{S}$ where it was correlated to the Cd-Zn solid solution [14]. In general, ternary E-ALD schemes were found to grow semiconducting materials layer by layer resulting in a deficiency of the less noble metal. We should report that only minor morphology changes are found in $\mathrm{Cd}_{\mathrm{x}} \mathrm{Zn}_{1-\mathrm{x}} \mathrm{S}$ with respect to the binary films ( $\mathrm{CdS}$ and $\mathrm{ZnS}$ ). Moreover, the roughness changes with the stoichiometry, reaching a minimum for $\mathrm{x}=0.28$ [15]. Conversely, for the $\mathrm{Cu}_{\mathrm{x}} \mathrm{Zn}_{\mathrm{y}} \mathrm{S}$ film the morphology is found to be dramatically different with respect to the $\mathrm{Cu}_{2} \mathrm{~S}$, presenting a thread-like structure of nanowires reaching the micrometer scale [16,17], whereas for $\mathrm{Cu}_{2} \mathrm{~S}$ a roughness of $24 \AA$ is reported elsewhere [7]. X-ray absorption spectroscopy experiments pointed to the possible influence of the $\mathrm{Zn}$ deposition step in the formation of the nanowires net in the $\mathrm{Cu}_{\mathrm{x}} \mathrm{Zn}_{\mathrm{y}} \mathrm{S}$ E-ALD scheme [16].

These studies pointed out that additional structural characterization is needed to improve the understanding of the growth process and determine the main structural features of the films grown by E-ALD. Thus, in the present study, we report the operando SXRD (Surface X-Ray Diffraction) structural characterization of $\mathrm{Cu}_{\mathrm{x}} \mathrm{Zn}_{\mathrm{y}} \mathrm{S}$ thin-films deposited by E-ALD on $\mathrm{Ag}(111)$ electrodes, with the aim of studying the growing of the film and to clarify the role of the $\mathrm{Zn}$ in the growth of the nanowires net.
Table 1

Samples presented in this study.

\begin{tabular}{lll}
\hline Label & Type & Description \\
\hline Op1:1 & $C u_{x} Z n_{y} S 1: 1(60$ cycles) & Grown operando at ESRF \\
Ex20 & $C u_{x} Z n_{y} S 1: 1(20$ cycles) & Grown ex-situ at UNIFI \\
Ex40 & $C u_{x} Z n_{y} S 1: 1(40$ cycles) & Grown ex-situ at UNIFI \\
Ex60 & $C u_{x} Z n_{y} S 1: 1(60$ cycles) & Grown ex-situ at UNIFI \\
\hline
\end{tabular}

\section{Methods}

\subsection{Experimental procedures}

The thin films were realized starting from analytical reagent grade materials: $\mathrm{Merck} \mathrm{CuCl}_{2}$, and Aldrich $\mathrm{Na}_{2} \mathrm{~S}$. Merck $\mathrm{HClO}_{4} 70 \%$ e Merck $\mathrm{NH}_{4} \mathrm{OH} 83 \%$ solutions were used for preparing a $9.2 \mathrm{pH}$ ammonia buffer. The solutions were freshly prepared just before each synthesis, using water purified by Milli-Q lab water system. In Table 1 we report the different thin films considered in this study. All syntheses were carried out by means of an automated deposition system, consisting of a distribution system composed of Pyrex bottles, electrochemical cells, a potentiostat, a control system for the solenoid valves and the stability of the potential $[18,19]$. This automated system allows a combination of the solutions within the electrochemical cell ensuring good fluid dynamics and a low contamination due to exposure to air. The four samples were grown in two different electrochemical flow cells, the first one designed for the E-ALD process, and the second specifically designed for coupling E-ALD with an operando SXRD investigation [3,20,21]. In both cases, the cell is delimited by the working electrode on one side and by the counter electrode on the other side, while the inlet and the outlet of the solutions were placed on the side walls [19]. A three-electrode scheme is used, with an Au counter electrode and an $\mathrm{Ag} / \mathrm{AgCl}$ ( $\mathrm{KCl}$ saturated) as a reference electrode. Concerning the synthesis, we use the following notation in reference to the $\mathrm{Cu} / \mathrm{Zn}$ ratio and the cycles grown: a sample of $\mathrm{Cu}_{\mathrm{x}} \mathrm{Zn}_{\mathrm{y}} \mathrm{S}$ with $\mathrm{n}=\mathrm{m}=1$ grown for 60 cycles is deposited through the following deposition sequence $\left[(\mathrm{S} / \mathrm{Cu} / \mathrm{S})_{n}(\mathrm{Zn} / \mathrm{S})_{\mathrm{m}}\right]_{60}$. The sample referred as "OP1:1" in Table 1 was investigated through operando SXRD during its growth, whereas samples Ex20, Ex40 and Ex60 were grown in the laboratory of the "Applied Electrochemistry" group at the University of Florence (UNIFI) and ex-situ analyzed. For the electrochemical parameters of the deposition process we refer to $[6,13]$. Commercial silver single crystal electrodes, prepared by the "Surface Preparation Laboratory B.V.", with (111) orientation were used for the growth of sample Op1:1. The electrode surface was cleaned under ultra-high vacuum conditions by performing several cycles of $\mathrm{Ar}^{+}$sputtering at $1 \mathrm{kV}$ followed by annealing at $900 \mathrm{~K}$ for about $1 \mathrm{~min}$. The cycles were repeated until a sharp low energy electron diffraction (LEED) pattern was observed and no contamination was observable by X-ray photoelectron spectroscopy (XPS).

Conversely, ex situ Ex20, Ex40 and Ex60 samples were grown on silver single crystal electrode with (111) orientation prepared according to the Bridgeman technique, in the laboratory of the "Applied Electrochemistry" group at the University of Florence [16] and polished by a $\mathrm{CrO}_{3}$ based procedure [22]. The operando measurements were performed at the ID03 beamline of European Synchrotron Radiation Facility (ESRF). The measurements were performed by means of the six circle vertical axis diffractometer installed in the EH1 hutch $[3,23]$. The diffracted intensity has been registered by means of a MAXIPIX fast readout areal detector [24]. The electrochemical cell was mounted on the diffractometer stage. All measurements were carried out using a $24 \mathrm{keV}$ X-ray radiation in order to allow a high transmission through the EC cell walls and solutions $[3,23]$. 


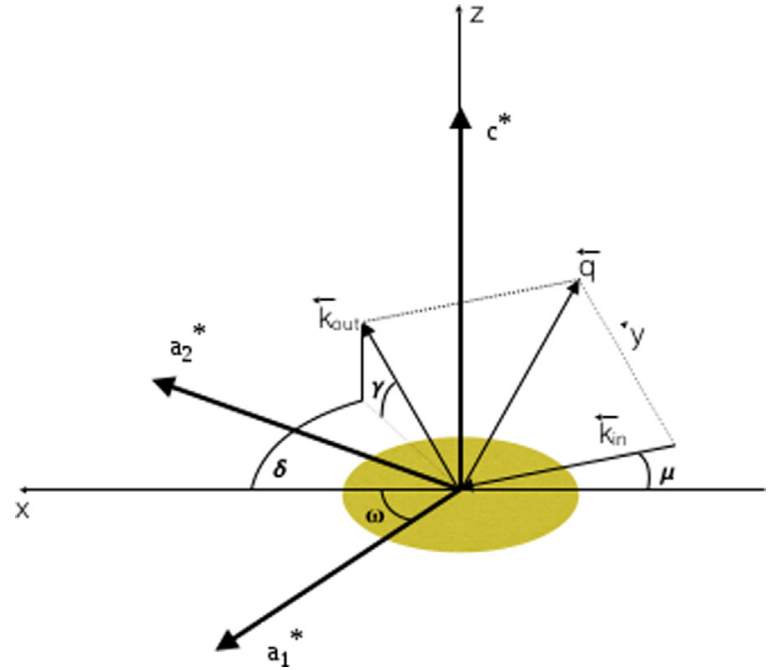

Fig. 1. A schematic layout of the SXRD geometry. The sample surface is represented by the yellowish disc. $x, y, z$ is the reference system of the laboratory while $a_{1}{ }^{*}, a_{2}$ and $c^{*}$ are the reciprocal vector of the $\mathrm{Ag}(111)$ surface cell used as reference system of the reciprocal space. In SXRD the $z$ axis and the $c^{*}$ vector are parallel. The sample surface is in the plane $\mathrm{x}, \mathrm{y}$ where also the vectors $\mathrm{a}_{1}{ }^{*}$ and $\mathrm{a}_{2}{ }^{*}$ lay. The angle $\omega$ is between the $\mathrm{a}_{1}{ }^{*}$ vector and the $\mathrm{x}$ axis is the azimuth angle. The incident $\mathrm{x}$-ray beam, $\mathrm{k}_{\mathrm{in}}$, is in the plane $\mathrm{x}, \mathrm{z}$ at an angle $\mu$ with the surface, The exit beam, $\mathrm{k}_{\text {out }}$, has an exit angle $\gamma$ with respect to the surface and an in plane angle $\delta$ with respect the $x, z$ plane. To measure the diffracted intensity in a particular point of the reciprocal space the $\delta$, $\gamma$ and $\omega$ angles are positioned while $\mu$ is maintained at fixed angle (typically $0.5^{\circ}-1^{\circ}$ for this experiment)

\subsection{Reciprocal space mapping strategy}

We performed the electrodeposition of Op1:1 while acquiring SXRD data of linear scans and 2D maps in the reciprocal space, to understand the evolution of the structural features of the deposited film during and after its growth. This operando procedure allowed us to monitor selected positions in the reciprocal space useful for the characterization of the structural properties of the $\mathrm{Cu}_{\mathrm{x}} \mathrm{Zn}_{\mathrm{y}} \mathrm{S}$ film.

The scans and the maps shown in this study are parameterized with respect to a coordinate system referred to the surface unit cell of the $\mathrm{Ag}$ (111) substrate. According to this convention, the correspondence between the standard fcc bulk Ag unit cell and the metric of the surface pseudo-hexagonal cell $\left(a_{1}, a_{2}, c, \alpha, \beta, \gamma\right)$ - where $a_{1}$ and $a_{2}$ vectors lay on the sample surface, while $c$ is perpendicular to that surface - is determined by the following relations:

$\alpha=\beta=90^{\circ}, \gamma=120^{\circ},|c|=\sqrt{3} a_{0},|a|=|b|=\frac{a_{0}}{\sqrt{2}}$

Where $\mathrm{a}_{0}$ is the lattice parameter of the cubic fcc cell of Ag. Having adopted this convention for the $\mathrm{a}_{1}, \mathrm{a}_{2}$ and c vectors, the reciprocal space is parameterized by the fundamental reciprocal vectors of the pseudohexagonal Ag structure, $\mathrm{a}_{1}{ }^{*}, \mathrm{a}_{2}{ }^{*}$ and $\mathrm{c}^{*}$. Where $\mathrm{a}_{1}$ and $\mathrm{a}_{2}$ are respectively the $[1 / 2-1 / 20]$ and the $[01 / 2-1 / 2]$ standard fcc vectors and define the plane parallel to the sample surface (referred as "inplane") and $\mathrm{c}$ is the standard fcc [ $\left.\begin{array}{lll}1 & 1 & 1\end{array}\right]$ vectors and perpendicular to the sample surface ("out of plane"). Any vector in the reciprocal space is represented by the $\mathrm{h}, \mathrm{k}$ and $\mathrm{l}$ coordinates, respectively, corresponding to the vectors component along the $\mathrm{a}_{1}{ }^{*}, \mathrm{a}_{2}{ }^{*}$ and $\mathrm{c}^{*}$ axis (Fig. 1), distances in the same space are expressed using reciprocal lattice units (rlu). The large sets of the diffraction data collected by the detector have been reduced using the Binoculars package: this procedure enables a correct evaluation of the Bragg peak intensities and the meshing in the reciprocal space of each pixel of the $2 \mathrm{D}$ detector $[24,25]$.

For the study of the film growth, we have registered l-scans in the reciprocal space acquired every 15 cycles. Those are spectra

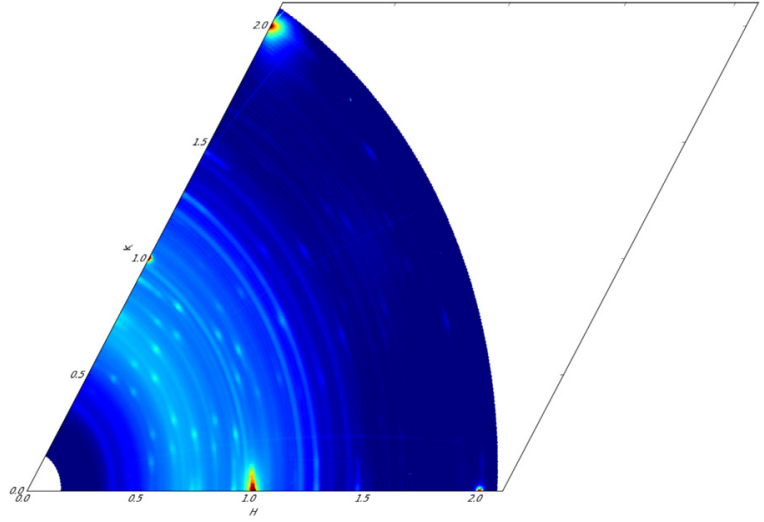

Fig. 2. Operando $h, k$ intensity maps at $l=1.05$ measured for the $0 p 1: 1$ sample.

where $\mathrm{h}$ and $\mathrm{k}$ are kept constant, while $\mathrm{l}$ is let vary in a range such as to explore the mutual space along a straight line.

2D scans have been collected after the 60th cycle, at the end of the synthesis, exploring $(\mathrm{h}, \mathrm{k})$ planes normal to $\mathrm{c}^{*}$ to compute large reciprocal space maps.

Moreover, XRPD (X-ray powder diffraction) spectra have been registered by means of $\delta$-scans (see Fig. 1), corresponding to an in-plane scan of the detector. This set up allows to explore the presence of Bragg cones at the horizon of the sample. To improve the sensitivity to the deposited film structure with respect to the one of substrate we used grazing angles for both the incident and diffracted beams and we choose an orientation $\omega$ of the sample azimuth such to avoid substrate Bragg peaks during the $\delta$-scans. XRPD patterns were registered every 15 cycles in the range $8-25^{\circ}$. XRPD data were refined by means of full-profile Rietveld algorithm, using the EXPO2014 software [26]. The removal of the diffuse scattering, introduced by the presence of the water inside the electrochemical cell, has been operated by fitting the background of the signals with polynomials (first order for the l-scans and 18 terms Chebyshev polynomial for the $\delta$-scans) [27].

\subsection{Single line profile analysis}

A single line analysis of the diffraction profile was performed by fitting a Voigt function. We present a profile analysis of a representative and reflection $(0.73,0.73,4.18)$ along the $(0.73,0.73,1)$ crystallographic direction by using a Voigt function, chosen on the basis of its intensity and small overlapping with other signals. As calculated by the geometry of the diffractometer, we can assume a negligible instrumental contribution to the profile breadth, while the peak width is dominated by the contributions due to the domain size and lattice strain [22]. Under these assumptions, the deconvolution of the Voigt profile can be computed assuming a Gaussian profile for the strain and a Lorentzian profile for the domain size [28-32]. The parameters used to analyze the peaks and the growing mechanism are the Gaussian width (wG), the Lorentzian width $(\mathrm{wL})$, the peak area $(\mathrm{A})$ and the peak position $\left(\mathrm{x}_{\mathrm{c}}\right)$. The relation between the strain and $w G$, as well as the relation between crystallites dimension and $w L$ is explained by de Keijser et al. [28]. According to these authors, wG is qualitatively correlated to the strain due to the distribution of defects (random distribution of defect-induced stresses). Relative uncertainties of the evaluated parameters (peak intensity, area and widths) were calculated by propagation of the experimental uncertainties of the intensity data. These latter were obtained as Root Mean Square (RMS) of the background. It is worth to notice that the data sets have been projected on the hkl space with a resolution of 0.001 rlu [26,27]. 

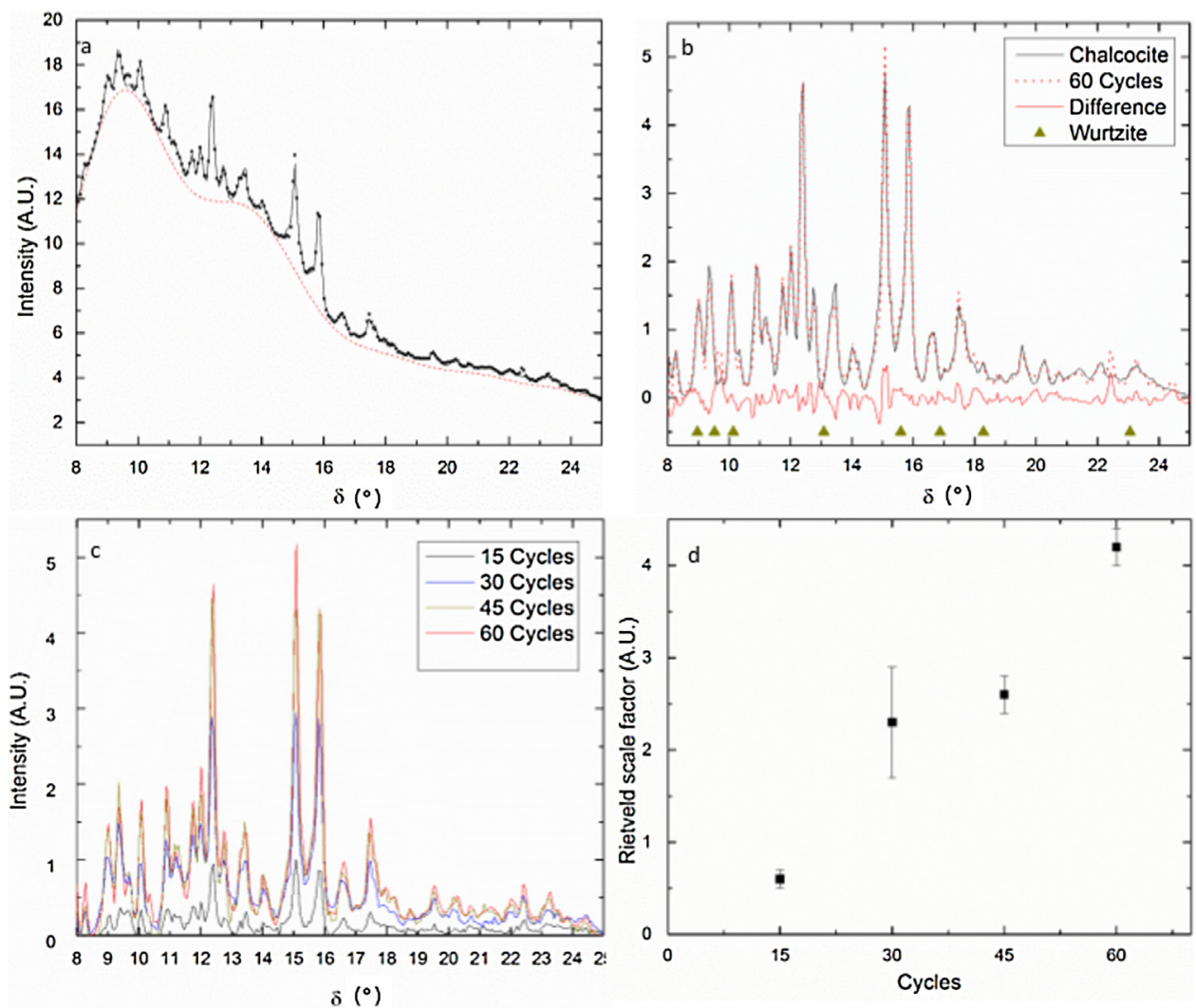

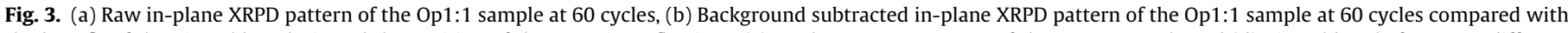

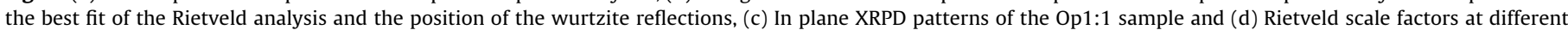
growth stages.

\subsection{SEM}

SEM investigations were carried out on ex-situ $\mathrm{Cu}_{\mathrm{x}} \mathrm{Zn}_{\mathrm{y}} \mathrm{S}$ samples with different stoichiometry, Ex20, Ex40 and Ex60 (Table 1), in order to determine the morphology of the films. The measurements were performed at the Interdepartmental center of Electronic Microscopy and Microanalysis (MEMA) of the University of Florence. To enhance the quality of the micrographs at high magnification, samples were gold coated. Secondary electron (SE) micrographs were obtained using a SEM ZEISS EVO MA15, by applying a potential of $20 \mathrm{kV}$ to the electron beam.

\section{Results}

Both pseudo single crystal patterns and powder are observed for the Op1:1 sample. The parameters obtained by SXRD are useful for studying the growth mechanism of the Op1:1 sample and carry out a structural characterization, albeit purely qualitative. The trends for the fit parameters with deposition cycles allowed us to get information on crystallites strain and size. Moreover, the Debye rings have been analyzed by means of standard XRPD approach.

\subsection{Maps 1:1}

The different peaks analyzed during the sample growth can be observed in the $(\mathrm{h}, \mathrm{k})$ intensity map measured at a constant L value of 1.04 rlu. The maps of Op1:1 reveal an apparent pseudo single crystal hexagonal pattern (Fig. 2), and the presence of rings. The dependence of the intensity along the 1 direction shows that the rings are due to phases almost perfectly oriented along the [ $\left[\begin{array}{lll}0 & 0 & 1\end{array}\right]$ direction. The reflections present as Bragg peaks have a periodicity and structure comparable to an ordered phase of $\mathrm{Cu}_{2} \mathrm{~S}$, already reported by our group elsewhere [16,17,33]. The operando crystallographic structure of the grown $\mathrm{Cu}_{2} \mathrm{~S}$ films has strong similarities with the one of the low chalcocite $[16,17,33]$, although the in-plane lattice parameters point to a different metric [21]. The structural model of $\mathrm{Cu}_{2} \mathrm{~S}$ proposed by these authors is based on a hexagonalclose-packed framework of S atoms. In this framework, $\mathrm{Cu}$ atoms are partially filling triangular voids within the $\mathrm{S}$ layers perpendicular to [ [ $\left.\begin{array}{lll}0 & 0 & 1\end{array}\right]$, and partially intercalated between adjacent $S$ layers parallel to the surface in an arrangement similar to natural chalcocite's structural model [35]. We also registered the presence of the characteristic Bragg peaks in the positions expected for wurtzite, i.e. (0 0.751 .13$)$. However, these Bragg peaks are very close to the peaks of the $\mathrm{Cu}_{2}$ S, i.e. $(00.73$ 1.04). Accordingly, the proximity of $\mathrm{ZnS}$ and $\mathrm{Cu}_{2} \mathrm{~S}$ reflections prevented a quantitative analysis. Eventually, superimposed to the Bragg reflections, a set of Debye rings can be identified (Fig. 2). These will be discussed in the following paragraph.

\subsection{Powder scans}

The $\delta$-scans were performed on the $0 p 1: 1$ sample at different stages of growth $(0,15,30,45$ and 60 cycles). The experimental XRPD spectrum of the sample Op1:1 at 60 cycles is shown in Fig. 3a. All reflections can be indexed according to the structure of monoclinic chalcocite (space group $P 2_{1} / c$, [34-40]). The small discrepancies between the Rietveld best fit and the experimental data are compatible with wurtzite structure (space group $P 6_{3} m c$ [41]). However, due to their small intensity, it is not possible to perform a quantitative analysis. No other reflections due to spurious products or relics of the precursors are evident (Fig. 3b). The nondimensional $\mathrm{R}$-Bragg values for the Rietveld fits are in the range of 4-10. Under the present experimental conditions, the minimum detection limit 

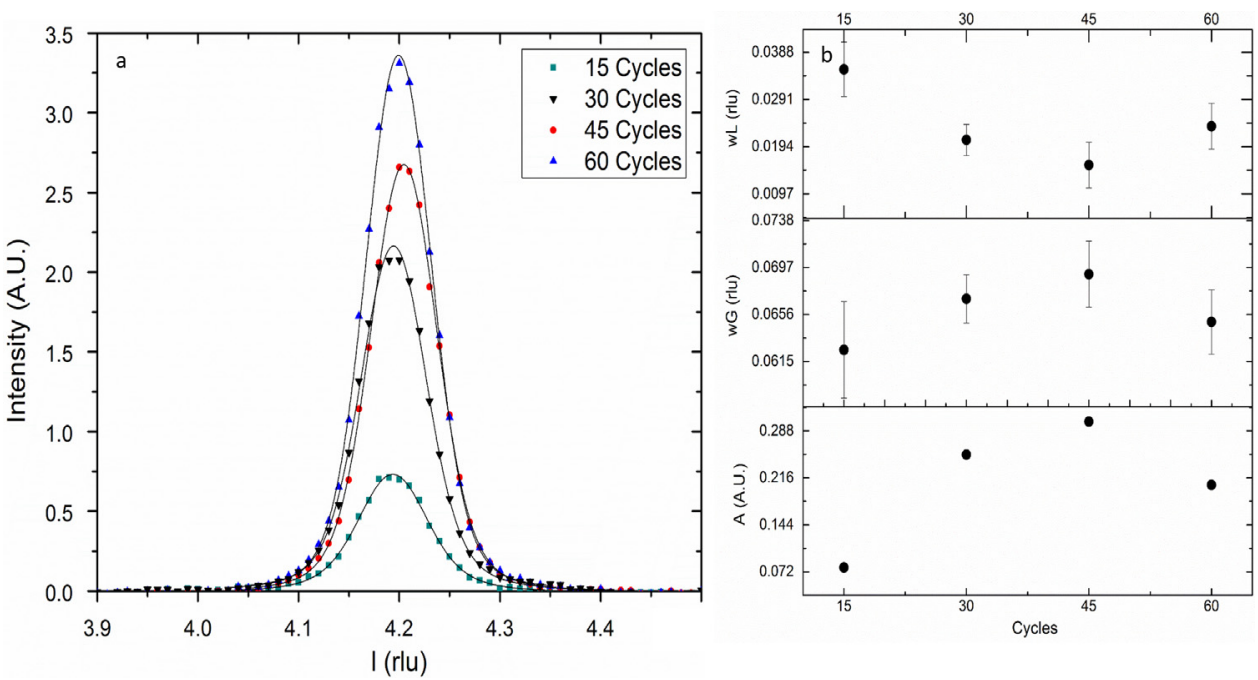

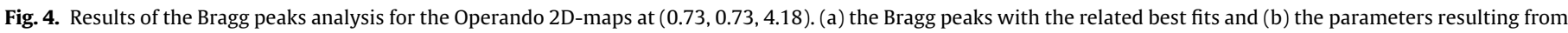
the best fits.

achievable for the method is no less than $1 \mathrm{wt} \%$. The $\delta$-scans are presented in Fig. 3c after the removal of the background signal from the diffuse scattering. The XRPD shows a constant growth of the disordered phase which seem to increase rapidly between the 45th and 60th cycles. This trend is quantitatively confirmed by the results of the Rietveld quantification, as illustrated by Fig. 3d, where we report the scale factor (i.e. a factor proportional to the total amount of chalcocite) versus a function of the number of E-ALD cycles. Apparently, the growth of chalcocite proceeds with a higher rate between the 15th and 30th and between the 45th and the 60th cycle, than between the 30 th and the 45 th deposition cycle.

\subsection{Single line profile analysis}

The growth process is studied by following the trends for the fit parameters obtained by single line profile analysis of the Bragg peaks in the Op1:1 sample. In the following, we present the growth parameters relating to the peak at $(0.73,0.73,4.18)$ presented in Fig. 4. Among the most intense, this peak has no overlapping with other signals and provides very reliable information [21,33]. The coordinates of this peak refer to a $\mathrm{Cu}_{2} \mathrm{~S}$ chalcocite-like crystal structure previously found in other studies. This peak allows us to study the growing process of the ordered $\mathrm{Cu}_{2} \mathrm{~S}$ phase with the deposition cycles. The peak profiles registered at the different number of deposition cycles are shown in Fig. 4a, together with the leastsquares best fit curves obtained using the Voigt function. There is a small change in the Bragg's peaks position during the growth (in the range 4.194-4.204) and with respect to the $\mathrm{Cu}_{2} \mathrm{~S}$ grown by means of the binary scheme (4.186 rlu) [21], these discrepancies are in the range $0.1 \%-0.4 \%$ comparable to the uncertainties of the positioning. Still, this difference is no greater than the uncertainties on the positioning that can be achieved with our setup.

The evolution of the most relevant parameters is shown in the graphs of Fig. 4b, where it is possible to observe the following trends: $w L$ decreases until the cycle 45 and then increases slightly: this can be related to an increase of crystallite size at least up to the 45 th cycle. The trend for wG is exactly the opposite, thus pointing to an increase of strain of the film until 45 cycle. The scale parameter A, which is related to the amount of deposited material, grows up to 45 cycle and then decreases slightly.

\subsection{Morphology}

As already reported for $\mathrm{Cu}_{\mathrm{x}} \mathrm{Zn}_{\mathrm{y}} \mathrm{S}$ 1:1 (60 cycles) the apparent thread of nanowires on the top of the electrode + film system points to the presence of at least a polycrystalline phase [16,17]. In Fig. 5 the morphology of the Ex20, Ex40 and Ex60 samples corresponding to different stages of growth for the $\mathrm{Cu}_{\mathrm{x}} \mathrm{Zn}_{\mathrm{y}} \mathrm{S} 1: 1$. The images reveal the lack of uniformity of the film. In particular, after 20 deposition cycles, the surface is no longer smooth, as it occurs for $\mathrm{Cu}_{2} \mathrm{~S}$ film [42]. The film, in fact, appears covered by several grains stepping ahead from its surface. After 40 cycles, these structures are replaced by nanowires with the length of the order of 1-2 $\mu \mathrm{m}$, and the thickness in the range of few tens of nanometers. After 60 cycles, the number, density and length of the nanowires is definitely increased, whereas the wire thickness has remained almost the same than before, in full agreement with previous studies on this type of film $[16,17]$. These evidences can be rationalized as it follows: the sample at 20 cycles represents an intermediate stage of the reorganization process; in fact, only starting from the 40th cycle, the formation of thread-like structures is observed. With the increasing number of deposition cycles, the morphology of the ternary compound becomes more complex, leading to the formation of nanoaggregate thread-like structures with length of several $\mu \mathrm{m}$.

\section{Discussion}

The whole set of the experimental data obtained in this study highlights, and confirms, the previous findings on the E-ALD films realized in the $\mathrm{Cu}-\mathrm{Zn}-\mathrm{S}$ system [16,17]. The data (Figs. 2 and 3), point out that ordered (pseudo-single crystal) and disordered polycrystalline phases are occurring in the sample Op1:1, as well as that the final product do contains two different $\mathrm{Cu}_{2} \mathrm{~S}$ phases, with different structural arrangements, and wurtzite $\mathrm{ZnS}$. This evidence apparently contrasts what already observed on other binary sulphides, including the $\mathrm{Cu}_{2} \mathrm{~S}$ itself $[33,34]$, and the ternary $\mathrm{Zn}-\mathrm{Cd}-\mathrm{S}$ films [14,15].

The set of pseudo-single crystal Bragg reflections has been assigned to the $\mathrm{Cu}_{2} \mathrm{~S}$ (chalcocite type) phase already reckoned during the operando SXRD study of the E-ALD grown binary copper sulfide $[33,34]$. The growth of the ordered phase is simultaneously accompanied by the formation of a disordered $\mathrm{Cu}_{2} \mathrm{~S}$ phase, this latter fully coincident with the natural low temperature chalcocite polymorph, the presence of which is also confirmed by the Debye rings present in the map of Fig. 2. The final assignment of this disordered phase was confirmed by means of Rietveld analysis (Fig. 3).

Concerning $\mathrm{ZnS}$, our data point to two possible phases in the sample, i.e. certainly a pseudo single crystal wurtzite and possibly a polycrystalline wurtzite. This result can be considered in line with 

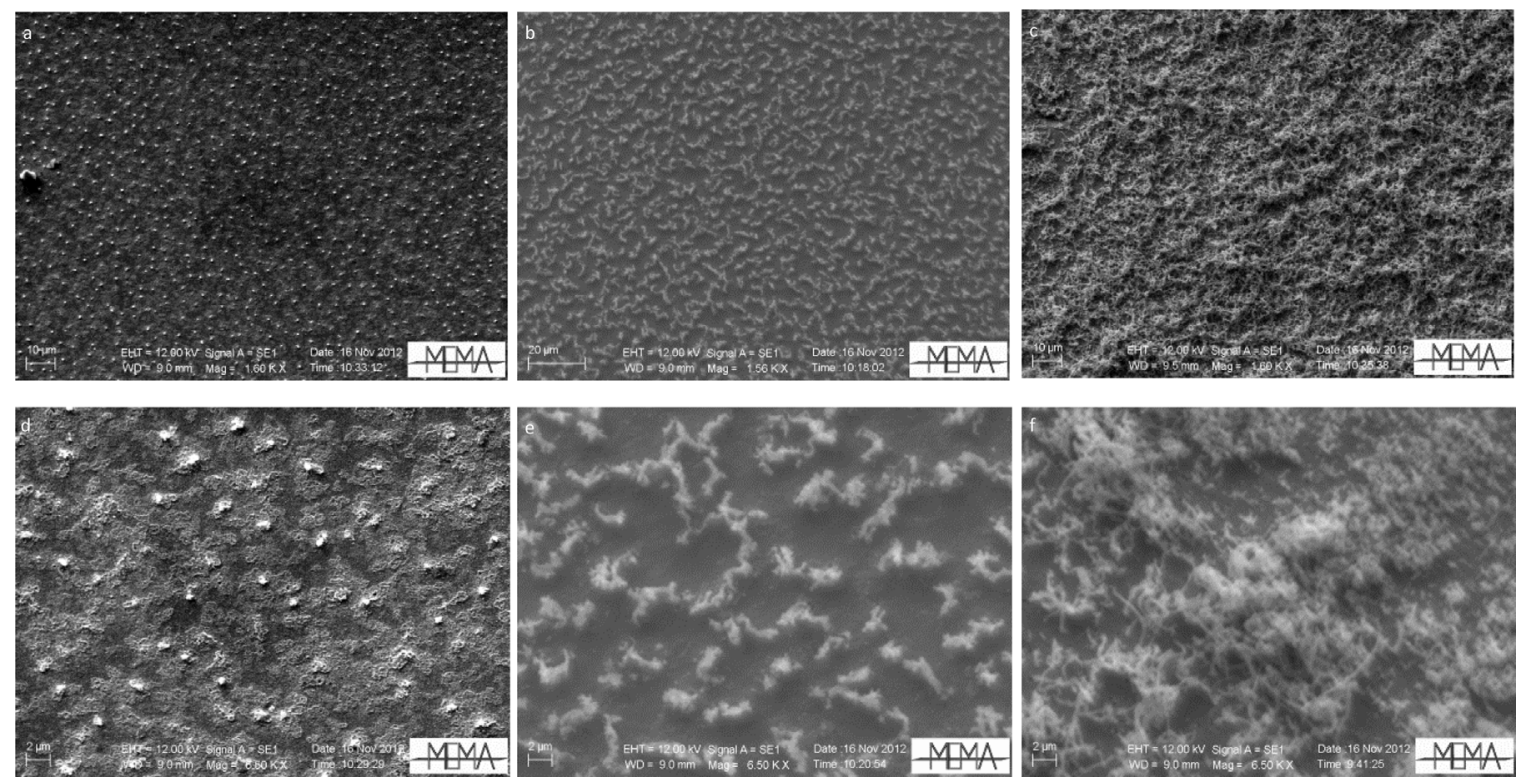

Fig. 5. Morphological analysis of the $\mathrm{Cu}_{\mathrm{x}} \mathrm{Zn} \mathrm{n}_{\mathrm{y}} \mathrm{S} 1: 1$ at $1000 \mathrm{X}$ (a), (b), (c) and at 6500X (d), (e), (f). (a) and (d) refer to Ex20, (b) (e) Ex40 while (c) (f) Ex60.

that of [16,17]: in their study, in fact, the presence of two phases $\mathrm{Cu}_{2} \mathrm{~S}$ and $\mathrm{ZnS}$ was derived from XAS spectroscopy. These authors have attributed $\mathrm{ZnS}$ either to wurtzite or to sphalerite polymorphs, with preference to the latter, but they were not able to finally solve this issue because of the short range structural environment investigated by the XAS technique around $\mathrm{Zn}$. The study of the trends of the $\mathrm{Cu}_{2} \mathrm{~S}$ crystallites strain and size (Fig. 4a) depicts an even more complex situation occurring during the crystal growth. These trends suggest a growth less ordered than the one for $\mathrm{Cu}_{2} \mathrm{~S}$ samples analyzed in previous studies [34]. The crystallite strain and size along the c-axis increase with the deposition cycles until the 45th cycle and then abruptly decreases; the same trend is followed by the value $A$, which is related to the amount of the ordered $\mathrm{Cu}_{2} \mathrm{~S}$ deposited. It is worth to notice that after the 45 th cycle, the amount of the polycrystalline phase increases, whereas that of the epitaxial phase decreases. In this context, the effect of the $\mathrm{Zn}$ deposition step emerges clearly. Since the intercalation of cycles dedicated to the deposition of $\mathrm{Zn}$-S layers is the only difference between the EALD scheme for the direct growth of $\mathrm{Cu}_{2} \mathrm{~S}$, the accumulation of the stress as well as the growth of the nanowires are straight related to the effect of the deposition of $\mathrm{Zn}$, and they are also probably joined by a cause-and-effect relationship. We suggest that the release of the stress leads to the abrupt increase of the amount of the polycrystalline phase during the last part of the growth. An opposite trend is recorded for the disordered pattern, for which the Rietveld scale factor obtained from the $\delta$-scans increases abruptly from the 45 th cycle to the 60th cycle (Fig. 3b). The micrographs for the exsitu samples registered the abrupt increase of a very complex net of nanowires between the 40th and 60th cycles (Fig. 5). Since no other diffraction signals were recorded on this system, the nanowires are attributed to the disordered phase observed by the $\delta$-scans, i.e. to $\mathrm{Cu}_{2} \mathrm{~S}$ chalcocite. Hence, the micrographs allow a visual confirmation of the abrupt increase of the disordered phase in the last part of the growth.

\section{Conclusion}

From the early stages of the growth, at least two phase are clearly present: an ordered phase (pseudo-single crystal) and a disordered (polycrystalline) phase, as confirmed by morphologi- cal and XRPD data. In general, the growth of the $\mathrm{Cu}_{\mathrm{x}} \mathrm{Zn} \mathrm{n}_{\mathrm{y}} \mathrm{S}$ by means of E-ALD seems to be driven by the occurrence of copper-sulphides structures, as expected from recent studies that revealed a strong Zn deficiency [6,14]. No other phases involving zinc sulphides, but wurtzite, are evident in the present work. However [16,17], have suggested the occurrence of the cubic $\mathrm{ZnS}$ polymorph, sphalerite. We rely on the present attribution of the $\mathrm{ZnS}$ phase, as the performed XRPD investigation properly deal with the long range arrangement of the structure.

The SXRD allowed the characterization of the changes in the features of the crystallites of the pseudo-single crystal and in the scale factors of both the pseudo-single crystal and the polycrystalline phase. These results points to the occurrence of a complex growth process involving an oriented and strained phase with a randomly oriented, polycrystalline phase growing on top of it. After the 45th cycle, most of the stress is released by increasing the amount of disordered phase, likely by means of a structural rearrangement or re-crystallization. Comparing the growth of Op 1:1 with the direct growth of $\mathrm{Cu}_{2} \mathrm{~S}$ [34] we reckoned a general increase of the strain, revealing a high concentration of randomly distributed structural defects in the $\mathrm{Cu}_{2} \mathrm{~S}$ epitaxial phase. Our hypothesis is that $\mathrm{Cu}$ vacancy or $\mathrm{Zn}$ inclusion in a defective $\mathrm{Cu}_{2} \mathrm{~S}$ structure explain the increased strain. In this context, the effect of the $\mathrm{Zn}$ deposition step emerges clearly, leading to accumulation of stress that seems to drive the growth of the nanowires, hence leading the abrupt increase of their amount during the last part of the growth. This work shed light on the structure and growth of $\mathrm{Cu}_{\mathrm{x}} \mathrm{Zn}_{\mathrm{y}} \mathrm{S}$ and the origin of its complex morphology. Such results suggest an unexpectedly complex growth mechanism of the $\mathrm{Cu}_{\mathrm{x}} \mathrm{Zn}_{\mathrm{y}} \mathrm{S}$ films deposited by means of E-ALD. In fact, as discussed lately in other similar papers $[21,43]$ the E-ALD growth, although surface limited, is probably not only the result of a layer-by-layer deposition, but most probably the product of multiple competitive processes including surface limited equilibria. Eventually, we should notice that such highly structured surfaces grows on top of a very ordered semiconducting surface and the overall product is obtained by means of very reproducible surface controlled scheme. Thus, it could be engineered to be applied in several fields where the growth of semiconducting material with high surface area is required (e.g. a photocatalytic material [44]). 


\section{Acknowledgements}

The Centro di Servizi di Microscopia Elettronica e Microanalisi (MEMA), Università Degli Studi di Firenze, is acknowledged for kindly granting the use of the Scanning Electron Microscopy, as well as Mario Paolieri and Maurizio Ulivi are acknowledged for their assistance in the same investigations. FDB and MI benefited for departmental funding (ex 60\%). CNR is acknowledged, for support. This work was fundamentally supported by the assistance in the Ag single crystal synthesis and preparation by Ferdinando Capolupo, at the Electrochemical Lab of the Dept. of Chemistry of the University of Florence. Ferdinando Capolupo is warmly acknowledged for it.

\section{References}

[1] M. Innocenti, F. Di Benedetto, A. Lavacchi, N. Cioffi, R. Felici, L.A. Pardi, Fabricating energy devices with low environmental impacts, SPIE Newsroom 2-4 (2016), http://dx.doi.org/10.1117/2.1201512.006249.

[2] B.W. Stickney, J.L. Gregory, Electrochemical atomic layer epitaxy (ecale), J. Electroanal. Chem. 300 (1991) 543-561.

[3] A. Giaccherini, R. Felici, M. Innocenti, Operando Structural Characterization of the E-ALD Process Ultra-Thin Films Growth, in: M. Khodaei (Ed.), X-ray Characterization of Nanostructured Energy Materials by Synchrotron Radiation (2017).

[4] European Commission, Critical Raw Materials for the EU, 2010

[5] S. Caporali, A. Tolstogouzov, O.M.N.D. Teodoro, M. Innocenti, F. Di Benedetto, S. Cinotti, et al., Sn-deficiency in the electrodeposited ternary CuxSnySz thin films by ECALE, Sol. Energy Mater. Sol. Cells 138 (2015) 9-16, http://dx.doi. org/10.1016/j.solmat.2015.02.029.

[6] M. Innocenti, L. Becucci, I. Bencistà, E. Carretti, S. Cinotti, L. Dei, et al., Electrochemical growth of Cu-Zn sulfides, J. Electroanal. Chem. 710 (2013) 17-21, http://dx.doi.org/10.1016/j.jelechem.2013.01.024.

[7] E. Acta, Electrochemical Layer by Layer Growth and Characterization of Copper Sulfur Thin Films on, 2011, http://dx.doi.org/10.1016/j.electacta.2011 10.004 .

[8] C.C. Uhuegbu, E.B. Babatunde, The study of copper zinc sulphide $\left(\mathrm{CuZnS}_{2}\right)$ thin films, J. Phys. 32 (2008) 39-47.

[9] A.I. Mukolu, K.A. Aduloju, Optical absorption and transmission in CuZnS alloys, Glob. J. Pure Appl. Sci. 15 (2009) 421-425

[10] N. Kitagawa, Copper zinc sulfur compound solar cells fabricated by spray pyrolysis deposition for solar cells, Nat. Resour. 04 (2013) 142-145, http://dx. doi.org/10.4236/nr.2013.41A018.

[11] P.B. Bagdare, S.B. Patil, A.K. Singh, Phase evolution and PEC performance of ZnxCd(1-x)S nanocrystalline thin films deposited by CBD, J. Alloys Compd. 506 (2010) 120-124, http://dx.doi.org/10.1016/j.jallcom.2010.06.152.

[12] M. Adelifard, H. Eshghi, M.M. Bagheri Mohagheghi, Synthesis and characterization of nanostructural CuS-ZnS binary compound thin films prepared by spray pyrolysis, Opt. Commun. 285 (2012) 4400-4404, http://dx. doi.org/10.1016/j.optcom.2012.06.030.

[13] M. Innocenti, S. Cinotti, I. Bencistà, E. Carretti, L. Becucci, F. Di Benedetto, et al., Electrochemical growth of Cu-Zn sulfides of various stoichiometries, ECS Trans. 161 (2014) D14-D17.

[14] F. Loglio, M. Innocenti, G. Pezzatini, M.L. Foresti, Ternary cadmium and zinc sulfides and selenides: electrodeposition by ECALE and electrochemical characterization, J. Electroanal. Chem. 562 (2004) 117-125, http://dx.doi.org/ 10.1016/j.jelechem.2003.08.016.

[15] M. Innocenti, S. Cattarin, F. Loglio, T. Cecconi, G. Seravalli, M.L. Foresti, Ternary cadmium and zinc sulfides: composition, morphology and photoelectrochemistry, Electrochim. Acta 49 (2004) 1327-1337, http://dx. doi.org/10.1016/j.electacta.2003.08.032.

[16] F. Di, S. Cinotti, F.D. Acapito, F. Vizza, M. Luisa, A. Guerri, et al., Electrodeposited semiconductors at room temperature: an X-ray Absorption Spectroscopy study of Cu-, Zn-, S-bearing thin fi Ims, Electrochim. Acta 179 (2015) 495-503, http://dx.doi.org/10.1016/j.electacta.2015.05.168.

[17] F. Di Benedetto, S. Cinotti, A. Guerri, A. De Luca, A. Lavacchi, G. Montegrossi, et al., Physical characterization of thin films of $\mathrm{Cu}_{\mathrm{x}} \mathrm{Zn}_{\mathrm{y}} \mathrm{S}_{\mathrm{z}}$ for photovoltaic applications, ECS Trans. 58 (2013) 59-65.

[18] B.M. Huang, L.P. Colletti, B.W. Gregory, J.L. Anderson, J.L. Stickney, Preliminary studies of the use of an automated flow-cell electrodeposition system for the formation of CdTe thin films by electrochemical atomic layer epitaxy, J. Electrochem. Soc. 142 (1995) 3007-3016, http://dx.doi.org/10.1149/1. 2048677.

[19] M.L. Foresti, M. Innocenti, G. Pezzatini, F. Forni, CdS and ZnS deposition on $\mathrm{Ag}(111)$ by electrochemical atomic layer epitaxy, J. Electrochem. Soc. 148 (2001) C357-C362

[20] M.L. Foresti, A. Pozzi, M. Innocenti, G. Pezzatini, F. Loglio, E. Salvietti, et al., In situ X-ray analysis under controlled potential conditions: An innovative setup and its application to the investigation of ultrathin films

electrodeposited on $\mathrm{Ag}\left(\begin{array}{lll}1 & 1 & 1\end{array}\right)$, Electrochim. Acta 51 (2006) 5532-5539, http:// dx.doi.org/10.1016/j.electacta.2006.02.031.

[21] A. Giaccherini, R. Felic, M. Innocenti, Operando structural characterization of the E-ALD process ultra-thin films growth, in: X-Ray Characterization of Nanostructured Energy Materials by Synchrotron Radiation, InTech, 2017, pp. $31-50$.

[22] M.L. Foresti, F. Capolupo, M. Innocenti, F. Loglio, Visual detection of crystallographic orientations of face-centered cubic single crystals, Cryst. Growth Des. 2 (2002) 73-77, http://dx.doi.org/10.1021/cg015537i.

[23] M. Luisa, A. Pozzi, M. Innocenti, G. Pezzatini, F. Loglio, E. Salvietti, et al., In situ $\mathrm{X}$-ray analysis under controlled potential conditions: an innovative setup and its application to the investigation of ultrathin films electrodeposited on $\mathrm{Ag}$ (111), Electrochim. Acta 51 (2006) 5532-5539, http://dx.doi.org/10.1016/j. electacta.2006.02.031.

[24] C. Ponchut, J.M. Rigal, J. Clément, E. Papillon, A. Homs, S. Petitdemange, MAXIPIX, a fast readout photon-counting X-ray area detector for synchrotron applications, J. Instrum. 6 (2011), http://dx.doi.org/10.1088/1748-0221/6/01/ C01069, C01069-C01069.

[25] A. Altomare, C. Cuocci, C. Giacovazzo, A. Moliterni, R. Rizzi, N. Corriero, et al. EXPO2013: a kit of tools for phasing crystal structures from powder data, J. Appl. Crystallogr. 46 (2013) 1231-1235, http://dx.doi.org/10.1107/ S0021889813013113.

[26] S. Roobol, W. Onderwaater, J. Drnec, R. Felici, J. Frenken, BINoculars Data reduction and analysis software for two-dimensional detectors in surface X-ray diffraction, J. Appl. Crystallogr. 48 (2015) 1324-1329, http://dx.doi.org/ 10.1107/S1600576715009607.

[27] J. Drnec, T. Zhou, S. Pintea, W. Onderwaater, E. Vlieg, G. Renaud, et al., Integration techniques for surface X-ray diffraction data obtained with a two-dimensional detector, J. Appl. Crystallogr. 47 (2014) 365-377, http://dx. doi.org/10.1107/S1600576713032342.

[28] T.H. de Keijser, J.I. Langford, E.J. Mittemeijer, A.B.P. Vogels, Use of the Voigt function in a single-line method for the analysis of X-ray diffraction line broadening, J. Appl. Crystallogr. 15 (1982) 308-314.

[29] J.I. Langford, Accuracy in powder diffraction, Natl. Bur. Stand. Spec. Publ. 567 (1980) 255-269.

[30] J.I. Langford, The variance and other measures of line broadening in powder diffractometry. I. Practical Considerations, J. Appl. Crystallogr. 1 (1968) 48-59, http://dx.doi.org/10.1107/S0021889868005182.

[31] B.E. Warren, B.L. Averbach, The effect of cold-work distortion on X-ray patterns, J. Appl. Phys. 21 (1950) 595.

[32] J.I. Langford, R. Delhez, T.H. de Keijser, E.J. Mittemeijer, Profile analysis for microcrystalline properties by the Fourier and other methods, Aust. J. Phys. 41 (1988) 173-187, http://dx.doi.org/10.1071/PH880173.

[33] A. Giaccherini, I. Bencista, S. Cinotti, G. Montegrossi, A. Guerri, F. Di Benedetto, et al., Synthesis and technological application of electrodeposited semiconductors by EC-ALD, ECS Trans. 58 (2014) 35-41, http://dx.doi.org/10. $1149 / 05832.0035$ ecst.

[34] A. Giaccherini, S. Cinotti, A. Guerri, F. Carlà, G. Montegrossi, F. Vizza, et al., Operando SXRD study of the structure and growth process of Cu2S ultra-thin films, Sci. Rep. (2017) (In-press).

[35] H.T. Evans, Crystal structure of low chalcocite, Nat. Phys. Sci. 232 (1971) 69-70, http://dx.doi.org/10.1038/physci232069a0.

[36] S. Gražulis, A. Daškevič, A. Merkys, D. Chateigner, L. Lutterotti, M. Quirós, et al., Crystallography Open Database (COD): an open-access collection of crystal structures and platform for world-wide collaboration, Nucleic Acids Res. 40 (2012) D420-D427, http://dx.doi.org/10.1093/nar/gkr900.

[37] A. Merkys, A. Vaitkus, J. Butkus, M. Okulič-Kazarinas, V. Kairys, S. Gražulis, COD:CIF:Parser. An error-correcting CIF parser for the Perl language, J. Appl. Crystallogr. 49 (2016) 292-301, http://dx.doi.org/10.1107/ S1600576715022396.

[38] S. Graulis, D. Chateigner, R.T. Downs, A.F.T. Yokochi, M. Quirós, L. Lutterotti, et al., Crystallography open database - an open-access collection of crystal structures, J. Appl. Crystallogr. 42 (2009) 726-729, http://dx.doi.org/10.1107/ S0021889809016690.

[39] R.T. Downs, M. Hall-Wallace, The american mineralogist crystal structure database, Am. Miner. 88 (2003) 247-250.

[40] S. Gražulis, A. Merkys, A. Vaitkus, M. Okulič-Kazarinas, Computing stoichiometric molecular composition from crystal structures, J. Appl. Crystallogr. 48 (2015) 85-91, http://dx.doi.org/10.1107/S1600576714025904.

[41] R.W.G. Wyckoff, Crystal Structures, 1963.

[42] M. Innocenti, I. Bencistà, S. Bellandi, C. Bianchini, F. Di Benedetto, A. Lavacchi, et al., Electrochemical layer by layer growth and characterization of copper

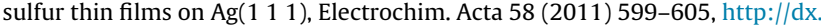
doi.org/10.1016/j.electacta.2011.10.004.

[43] F. Carlà, F. Loglio, A. Resta, R. Felici, E. Lastraioli, M. Innocenti, et al., Electrochemical atomic layer deposition of CdS on Ag single crystals: effects of substrate orientation on film structure, J. Phys. Chem. C 118 (2014) 6132-6139, http://dx.doi.org/10.1021/jp405637g.

[44] T. Jafari, E. Moharreri, A. Amin, R. Miao, W. Song, S. Suib, Photocatalytic water splitting-the untamed dream: a review of recent advances, Molecules 21 (2016) 900, http://dx.doi.org/10.3390/molecules21070900. 